\title{
III-V Nitrides for Electronic and Optoelectronic Applications
}

\author{
ROBERT F. DAVIS
}

Continued development and commercialization of optoelectronic devices, including light-emitting diodes and semiconductor lasers produced from III-V gallium arsenide-based materials, has also generated interest in the much wider bandgap semiconductor mononitride materials containing boron, aluminum, gallium, and indium. The majority of the studies have been conducted on pure gallium nitride thin films having the wurtzite structure, and this emphasis continues to the present day. However, recent research has resulted in the fabrication of p-n junctions in cubic boron nitride, the deposition of cubic gallium nitride, as well as the fabrication of multilayer heterostructures and the formation of thin film solid solutions. Chemical vapor deposition (CVD) has usually been the technique of choice for thin film fabrication. However, more recently these materials have also been deposited by plasma-assisted CVD, reactive ionized-cluster beam deposition, and reactive and ionized molecular beam epitaxy. The objective of this paper will be to review the recent developments in all the III-V nitride thin film materials vis a vis electronic and optoelectronic applications.

\section{INTRODUCTION}

The commercial realization of light emitting diodes and semiconductor lasers in the previous decade generated much interest in thin films of the wider bandgap semiconductor III-V mononitrides, especially GaN. As noted in Table 1, the latter material, in the wurtzite form, has a bandgap of $3.45 \mathrm{eV}$ (near UV region) at room temperature. It also forms a continuous range of solid solutions with AlN $(6.28 \mathrm{eV})$ and $\operatorname{InN}(1.95 \mathrm{eV})$. Thus optoelectronic devices having specifically engineered bandgaps with energies from the visible to the deep UV region are theoretically possible with these materials. The wide bandgaps of these materials and their strong atomic bonding also makes them candidates for high-power and high-temperature devices, assuming appropriate doping impurities are available and can be incorporated on the crystal lattice sites.

By contrast, films of cubic(c) BN have been of interest primarily for wear and corrosion resistant, electrically

Manuscript received October 24, 1990; revised December 16, 1990. This work was supported by the Office of Naval Research under Contract N00014-86-K-0686 P4.

The author is with the Department of Materials Science and Engineering, North Carolina State University, Raleigh, NC 27695-7907.

IEEE Log Number 9144570
Table 1 Comparison of the lattice parameters and bandgaps of the III-V mononitrides

\begin{tabular}{lllll}
\hline Material & Structure & $\mathrm{a}$ & $\mathrm{c}$ & $\begin{array}{l}\text { Bandgap } \\
(\mathrm{eV})\end{array}$ \\
\hline BN & zincblende & 3.615 & 3.615 & $\begin{array}{l}6.4 \pm \\
0.2(\mathrm{I})^{*}\end{array}$ \\
& & & & $6.28(\mathrm{D})^{*}$ \\
AIN & wurtzite & 3.11 & 4.98 & $3.45(\mathrm{D})^{*}$ \\
GaN & wurtzite & 3.19 & 5.19 & $3.26(\mathrm{D})^{*}$ \\
& zincblende & 4.54 & 4.54 & $1.95(\mathrm{D})^{*}$ \\
\hline
\end{tabular}

"I indicates indirect bandgap; D indicates direct bandgap.

insulating and passivating surfaces which can be used in high temperature and/or corrosive environments. Cubic BN also has considerable applications in the machining of steels where diamond tools cause problems as a result of the transfer of $\mathrm{C}$ into the metal following transformation to graphite at the hot interface. Moreover, electrically active, moderately shallow $n$ - and p-type dopants exist for $\mathrm{cBN}$, and considerable interest in this material for microelectronic applications has been stimulated by the recent creation of a $\mathrm{p}-\mathrm{n}$ junction diode having a portion of its emission spectra in the ultraviolet.

In the following subsections, reviews of the development of thin films of these materials and their current status are presented. The problems which are currently limiting the development of these materials and devices made from them are also discussed.

\section{REVIEW ANd CURRent Status Of III-V} NiTRIDES WITH AN EMPHASIS ON ELECTRONIC AND OPTOELECTRONIC APPLICATIONS

\section{A. Cubic Boron Nitride}

Boron nitride has no counterpart in nature. By analogy to $\mathrm{C}$, it exists as a soft, hexagonal, graphite-like material; as 
an extremely hard cubic form (zincblende structure); and as an equally hard hexagonal ((hBN) wurtzite) form [1]. The graphitic form of $\mathrm{BN}$ is used as a refractory material and a lubricant. The cubic form is produced under equilibrium conditions only at high temperatures and high pressures [2]. It is used primarily as an abrasive grain. But it is this material which is now attracting attention in terms of synthesis at lower temperatures and pressures in a manner recently developed for diamond. The applications would be for hard coatings and high-power, high-temperature electronics.

The first experimental evidence for the fabrication of either hBN or $\mathrm{cBN}$ under nonequilibrium conditions was reported by Sokolowski [3]. He used a reactive pulse plasma crystallization technique which involved an electric discharge between electrodes made of $\mathrm{B}$ and $\mathrm{Cu}$ contained in an atmosphere of $3: 1 \mathrm{~N}_{2}$ and $\mathrm{H}_{2}$. The plasma reaction products were thin layers containing $\mathrm{B}$ and $\mathrm{N}$ which were deposited on metal substrates held at $300 \mathrm{~K}$. The primary phase which occurred was hBN. This research was subsequently expanded by Weissmantel and coworkers [4]-[6] who formed hard films with characteristics of $\mathrm{cBN}$ using both ion beam plating of electron-beam evaporated $\mathrm{B}$ and $\mathrm{N}_{2}$ ions and ion beam deposition using the precursor of borazine $\left(\mathrm{B}_{3} \mathrm{~N}_{3} \mathrm{H}_{6}\right)$. The substrates were not heated. These investigators referred to this material as "i-BN" to indicate the critical role of ion bombardment in the growth process. The films were mostly amorphous, but contained $5-20 \mathrm{~nm}$ cBN crystallites. Electron energy loss spectroscopy results confirmed the presence of this crystalline phase. These investigators also employed a dual ion beam technique involving (1) a sputtered beam from a $\mathrm{B}$ or $\mathrm{BN}$ target and (2) an $\mathrm{N}$ ion beam.

Weissmantel et al. [6] noted that the properties of the films were very dependent upon processing conditions, however, the relationships were never defined. They suggested that ionic species were essential to the process, although this was not confirmed experimentally. A criticism of the techniques is that they were not configured such as to provide a systematic identification of the species involved in the reaction, thus making improvements in the film quality difficult.

Shanfield and Wolfson [7] also extracted ions from a borazine plasma using a Kaufmann source and accelerated them to $100 \mathrm{eV}$ onto the substrate. X-ray spectra of the samples showed peaks of $\mathrm{cBN}$. Auger analysis yielded a $\mathrm{B} / \mathrm{N}$ ratio of $1: 1$. Almost simultaneous with this research was that of Satou and Fujimoto [8] who employed a sophisticated combination of the electron beam evaporation of $\mathrm{B}$ and the production of $\mathrm{N}_{2}{ }^{+}$ions. The latter species were derived from a Penning discharge source used for plasma generation and accelerated through a magnetic sector for mass and energy analysis. The $\mathrm{N}_{2}{ }^{+}$ions also passed through a focusing magnetic lens system and a suppressor which controlled the secondary electron output from the Ta and $\mathrm{NaCl}$ substrates. The evaporation of the $\mathrm{B}$ and the $\mathrm{N}_{2}{ }^{+}$ bombardment of the substrates occurred simultaneously. Their deposition rates were controlled separately using a thickness monitor for $\mathrm{B}$ and by the beam current for $\mathrm{N}_{2}{ }^{+}$. The substrates were maintained at room temperature. Various N/B ratios were used. The resistivity of the films increased markedly at a ratio of 1.0. At a ratio of $1.8, \mathrm{~N}$ was incorporated in the form of bubbles, and the films were amorphous (or extremely fine grained). At a ratio of 2.5, fairly large grains of $\mathrm{hBN}$ (wurtzite) and $\mathrm{cBN}$ were observed by electron microscopy and selected area diffraction. No information regarding the better substrate for deposition was noted.

In research conducted by Chopra et al. [9] and more recently by Lin et al. [10] a modified activated reactive evaporation (ARE) process was used to prepare coatings containing cBN via evaporation of $\mathrm{H}_{3} \mathrm{BO}_{3}$ in an $\mathrm{NH}_{3}$ plasma. ARE involves the electron beam or resistance heated evaporation of a metal or a compound in the presence of a reactive gas. In this case, the $\mathrm{B}_{2} \mathrm{O}_{3}$ formed by the decomposition of $\mathrm{H}_{3} \mathrm{BO}_{3}$ was reduced by atomic $\mathrm{H}$ to $\mathrm{B}$ which reacted with the atomic $\mathrm{N}$ produced in the plasma to form BN. Various substrates including steel and fused quartz as well as $\mathrm{Si}$ and $\mathrm{NaCl}$ single crystals were used. Microstructural (TEM and selected area diffraction), optical (UV-IR transmission spectra and optical band gap measurements) and hardness studies indicated the existence of the zincblende [9] or a simple cubic (a most unusual form) [10] structure of $\mathrm{cBN}$ in the polycrystalline films. No hexagonal phase was detected.

Inagawa and coworkers [11] have borrowed from the research of the previous investigators in their use of electron beam evaporated $\mathrm{B}$ (with either a standard $270^{\circ}$ deflection type gun or a hollow cathode discharge gun) and plasma activated $\mathrm{N}$ to deposit $\mathrm{cBN}$ on substrates RF biased in the range of 0 to $-600 \mathrm{~V}$. The schematics of this equipment are shown in Fig. 1. The simultaneous addition of Ar into the $\mathrm{N}$ plasma considerably assisted the formation of $\mathrm{cBN}$, as shown in Figs. 2 and 3. At an $\operatorname{Ar} / \mathrm{N}_{2}$ ratio of $4: 1$, the films contained virtually $100 \%$ of the cubic phase.

A more recently published study of $\mathrm{cBN}$ deposition using electron beam evaporation and an electrical arc to create a plasma (reactive ion plating technique) has been that of Ikeda et al. [12]. The Si substrate was held at $725 \mathrm{~K}$. An RF bias was also applied to the substrate. It was determined that the bias potential played an important role in the formation of the cBN films. Infrared spectra revealed the presence of $\mathrm{cBN}$, and TEM showed that the microstructure consisted of $100 \AA$ average diameter grains of cBN deposited on an amorphous BN layer located on the substrate surface.

Wiggins et al. [13] and Seidel et al. [14] have used RF reactive sputtering. The structure of the film was not determined in the former study, however $\mathrm{cBN}$ was obtained in the latter research. Sharp diffraction rings were obtained in TEM when the bias potential was increased to a maximum of $-33 \%$ in combination with an increase in the partial pressure of $\mathrm{N}_{2}$ to a maximum of $1.3 \times 10^{-2}$ mbar $\left(P_{\text {total }}=\right.$ $2 \times 10^{-2}$ mbar). This corresponded to nearly stoichiometric films. The films consisted of microcrystals with diameters in the range from $50-t 0-1000 \AA$. Calculation of the lattice parameter from the diffraction patterns corresponded to the 

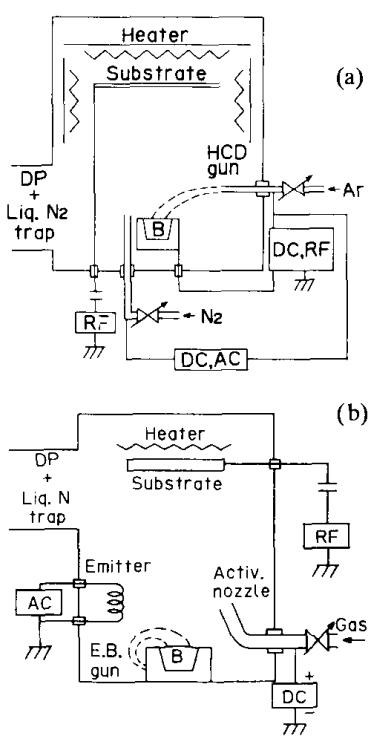

Fig. 1. (a) A schematic diagram of modified hollow cathode discharge-activated reactive (ARE) evaporation method. (b) A schematic diagram of the modified ARE method using a conventional $270^{\circ}$ electron beam gun [11].

$3.61 \AA$ for cBN. It was estimated that nearly the whole film consisted of $\mathrm{cBN}$ microcrystals. Raising the substrate temperature from ambient to $573 \mathrm{~K}$ did not markedly change the microstructure or the diffraction patterns of the films.

As noted in the first paragraph of this subsection, cBN is a nonequilibrium phase at the temperatures and pressures used in the experimental programs described above. As such, nonequilibrium routes which imparted additional internal and activation energies to both the $B$ and especially the $\mathrm{N}_{2}$ have been used to ensure that a higher energy phase would be deposited. Successful deposition of $\mathrm{cBN}$ has been attained. However, as pointed in a recent review by Arya and D'Amico [15] concerning the preparation, properties, and applications of $\mathrm{BN}$, the films have been polycrystalline and mixed with other amorphous or hexagonal phases of BN.

The one apparent exception to the last statement is the recent work of Doll et al. [16]. These investigators used laser (KrF) ablation of hot pressed or pyrolytic BN (both forms have the graphitic structure) in an ultrahigh purity $\mathrm{N}_{2}$ environment $\left((1-10) \times 10^{-2}\right.$ torr) to achieve the first successful heteroepitaxial growth of pure $\mathrm{cBN}$. The laser operating conditions included a fluence of $1.5 \mathrm{~J} / \mathrm{cm}^{2}$, pulse length of $22 \mathrm{~ns}$, power density of 0.2 gigawatts $/ \mathrm{cm}^{2}$ and a frequency of $6 \mathrm{kHz}$. The optimum temperature for the Si (001) substrates was $673 \mathrm{~K}$. Numerous $20-40 \mathrm{~m}$ diameter pinholes in the films at this temperature may have some strain accommodation-related importance regarding the achievement of pure $\mathrm{cBN}$, as they were absent under conditions (higher and lower temperatures) where it did not occur or was present to a limited extent. Electron diffraction showed preferred orientation of the (011) plane of the very

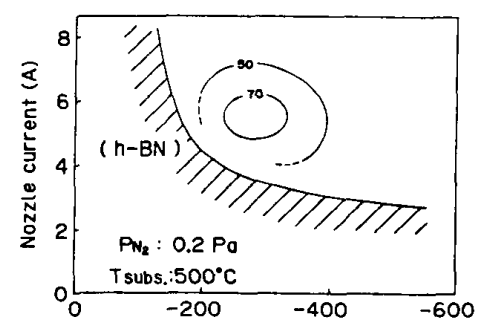

(a)

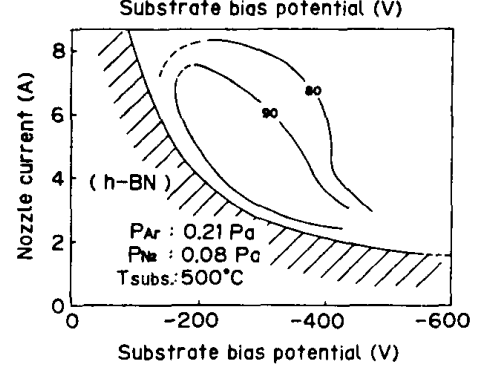

(b)

Fig. 2. (a) A distribution topograph showing the percentage of $\mathrm{cBN}$ in the films deposited by conventional electron beam evaporation in pure $\mathrm{N}_{2}$. (b) A distribution topograph showing the percentage of cubic phase in $\mathrm{BN}$ film obtained by conventional electron beam evaporation in a mixture of $\mathrm{N}_{2}+\mathrm{Ar}[11]$.

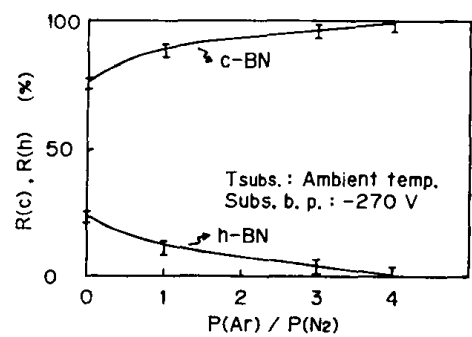

Fig. 3. Percentages of cubic and hexagonal phases in the $B N$ films obtained by the conventional EB evaporation in varying $\mathrm{P}(\mathrm{Ar}) / \mathrm{P}\left(\mathrm{N}_{2}\right)$ ratios [11]

small grain size polycrystalline cBN with the $\mathrm{Si}(001)$ plane; the planar spacing is such that three times the value for $\mathrm{Si}$ is within $1 \%$ of twice the value of $\mathrm{cBN}$. $\mathrm{X}$-ray and electron diffraction showed the $\mathrm{cBN}$ lattice constant to be $3.615 \AA$ or exactly that expected for this material. They examined the ablated plume with a second laser and found $\mathrm{B}^{+}, \mathrm{B}_{2}$, and $\mathrm{N}_{2}$ but no BN molecules. Apparently the $\mathrm{cBN}$ forms and grows at the Si surface. Auger electron spectroscopy indicated a homogeneous nonstoichiometry of $\mathrm{BN}_{0.8}$; however, the $\mathrm{N} / \mathrm{B}$ ratio could be increased if $\mathrm{NH}_{3}$ was used. Device fabrication on these films is being contemplated by the investigators.

At this writing, the only devices in $\mathrm{cBN}$ have been recently produced under high-pressure conditions. Mishima et al. [17] have fabricated p-n junctions in cBN single crystals by growing the initial crystal in a solvent of $\mathrm{LiCaBN}_{2}$ containing the donor dopant of $\mathrm{Si}$ under the conditions of $55 \mathrm{kbar}$ and $2075 \mathrm{~K}$ (at the cBN seed crystal) using a temperature difference method. The second crystal 


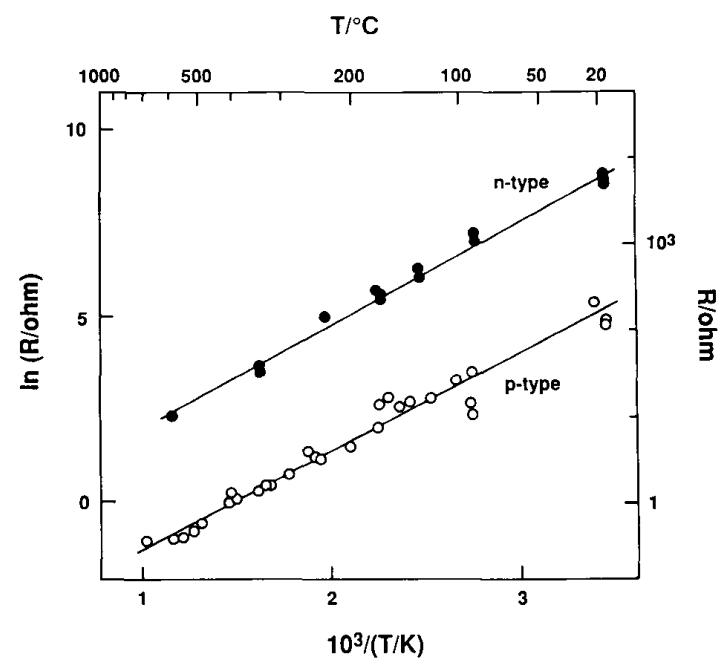

Fig. 4. Temperature dependence of the resistance of $n$ - and $p$ - doped cBN crystals. The p-type crystals were B-doped; the n-type material was Si-doped [17]

surrounded the first and was obtained under the same conditions except that the solvent contained the acceptor species of $\mathrm{Be}$. The resistance of the individual Be-doped and $\mathrm{Si}$-doped crystals at room temperature was $10^{2}-10^{3}$, and $10^{3}-10^{4}$, respectively, while that of the undoped crystal was $>10^{6}$. The temperature dependence of the resistance of each of these materials is shown in Fig. 4 to $\approx 873 \mathrm{~K}$. The activation energies for the $\mathrm{Be}$ - and Si-doped materials, estimated from the slopes of the lines in Fig. 4, are $0.23+$ $0.02 \mathrm{eV}$ and $0.24+0.03 \mathrm{eV}$, respectively.

The diode was functional from room temperature to 923 $\mathrm{K}$ [18], as shown in Fig. 5. The measurement became unstable with the onset of a large leakage current at 973 $\mathrm{K}$. Finally, injection luminescence in the ultraviolet was observed for the first time [18]. As shown in Fig. 6, the total spectra extended from $\sim 215 \mathrm{~nm}$ to the red with a few peaks in the ultraviolet. Curves A and B in Fig. 6 are injection luminescence spectra under forward bias conditions with the junction currents indicated. The two patterns are likely a result of crystal nonuniformity, especially in doping and reproduciblity in forming the electrode.

The principal roadblocks to the development of the high pressure technique is the resulting crystal size and the necessity to use the high pressure batch process. In addition, good ohmic contacts to $\mathrm{n}$ - and p-type material must be found and suitable insulating materials and methods of dry etching must be developed if high-power, high-frequency, and high-temperature devices are to be realized even from the materials produced at high pressures.

\section{B. Aluminum Nitride}

The properties of AlN indicate that it has great potential for several applications. The direct band gap of $6.28 \mathrm{eV}$ [19] suggests the possibility of windows which would transmit light in the ultraviolet region of the spectra and,

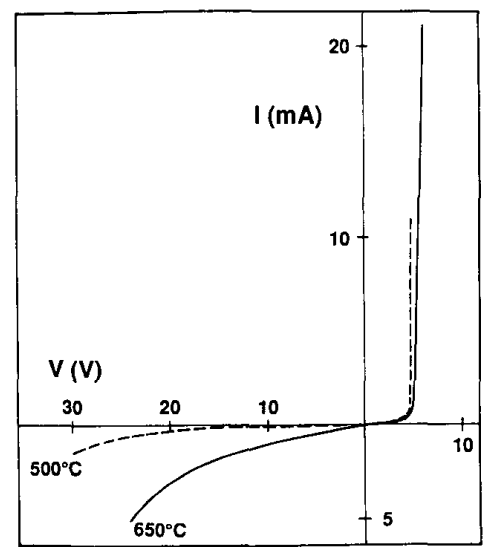

Fig. 5. Rectification characteristics at $500^{\circ} \mathrm{C}$ and $650^{\circ} \mathrm{C}$ of a $\mathrm{cBN}$ junction diode. (Private communication.)

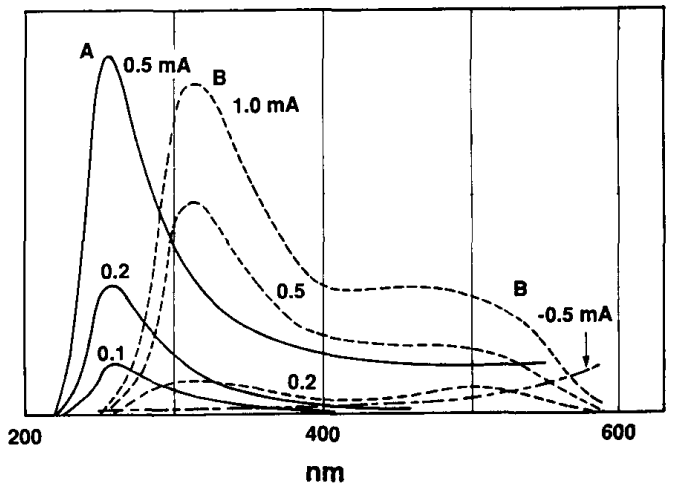

Fig. 6. Injection luminescence spectra under forward bias of p-n junction in $\mathrm{cBN}$ with junction currents as indicated. (Private communication.)

if properly doped, optoelectronic devices which would emit light in the same spectral region. Second harmonic generators have also been proposed to make use of the high nonlinear optical susceptibilities [20]. This material also possesses the highest reported surface acoustic wave velocity (Raleigh $V_{R}=6-6.2 \mathrm{~km} / \mathrm{s}$, longitudinal $V_{L}=11-12$ $\mathrm{km} / \mathrm{s}[21]-[23])$ reported for any material and a substantial electromechanical coupling coefficient (to 1\% [24]). In addition, it is distinguished by high hardness (1800 on Knoop scale), chemical stability, transparency in the visible, infrared (and ultra-violet) ranges, a melting point in excess of $2275 \mathrm{~K}$ [25], high electrical resistivity ( $\rho \geq$ $10^{13} \mathrm{~cm}$ ) and excellent thermal conductivity. These last two properties coupled with a static dielectric constant of $\approx 9.0$ have been commercially exploited in recent years in the manufacture of sintered polycrystalline ceramic heat sinks and substrates for semiconductor chips [29]. The material is also unaffected by electromagnetic radiation, electron and ion bombardment or shock waves (to $59 \mathrm{GPa}$ ) [26]. These properties (especially the acoustic) strongly indicate that superior surface acoustic wave devices, operational in aggressive media and under extreme conditions both 
as sensors for high temperatures and pressures and as acousto-optic devices [21]-[23], [24] can be developed. However, progress regarding these (and other) applications is hampered by the lack of good single crystals. To this end, several studies have been directed toward the achievement of monocrystalline films of this material.

The research conducted prior to 1975 has been reviewed extensively by Duffy [28]. In brief, reactive sputtering, plasma discharge, sublimation, and chemical vapor deposition (CVD) were used in this earlier period, with CVD being by far the most widely employed. Aluminum nitride films having single crystal character were deposited on Si, $\alpha-\mathrm{Al}_{2} \mathrm{O}_{3}$ (sapphire), $\mathrm{MgAl}_{2} \mathrm{O}_{4}$, and $\alpha-\mathrm{SiC}$ [29]-[37]. Sapphire has been by far the most common substrate. In a majority of these studies, the deposition process involved a reaction at elevated temperatures between either $\mathrm{AlCl}_{3}$ and $\mathrm{NH}_{3}$ or $\mathrm{Al}\left(\mathrm{CH}_{3}\right)_{3}$ and $\mathrm{NH}_{3}$. Yim and coworkers [19] and Callaghan et al. [35] noted that several orientations of AlN with varying degrees of crystalline perfection may be produced simultaneously on (01 $\overline{1} 2)$-oriented (R-plane) sapphire substrates by the chloride process. In contrast, AlN films grown by the metal-organic process are $(11 \overline{2} 0)$ oriented (A-plane) [34], [36], [37]. This latter orientation is of greatest interest for surface acoustic wave applications. Unfortunately, essentially all the films grown on sapphire using either the chemistries or the crystallographic planes noted above resulted in highly faceted films (see [28] for a collection of micrographs on various sapphire planes).

Liu et al. [37] also deposited films on polished surfaces of previously grown AlN films. However, the microstructure of the original films and those deposited on AlN surfaces were similar in appearance. Numerous morphological features including scale-like structures, ridge-like formations, and "bow-tie" shaped grains were evident. Preliminary results indicated that the interfacial strain extended approximately $1 \mu \mathrm{m}$ into the AIN film. Surface acoustic properties were also measured and found to strongly correlate with the quality of the AlN films.

Recent AIN deposition programs have used either past techniques with some modifications to the equipment and/or a change in the reactant species or a completely different approach. An example of the latter is the study by Harper and coworkers [38] who used a dual ion beam technique to supply a flux of $\mathrm{Al}$ from the $\mathrm{Ar}^{+}$ion beam $(1500 \mathrm{eV}$, $37 \mathrm{~mA}$ ) sputtering of an $\mathrm{Al}$ target simultaneous with the low energy $\mathrm{N}_{2}{ }^{+}(100-500 \mathrm{eV}, 8 \mathrm{~mA})$ bombardment of the growing film. All films were deposited on graphite substrates at ambient temperature. In this reactive deposition of AlN, ion-assisted chemistry (i.e., collisionally induced dissociative $\mathrm{N}_{2}$ chemisorption), trapping and preferential sputtering all played strong roles in controlling the film composition. A wide range of arrival rate ratios $(0 \leq \mathrm{N} / \mathrm{Al}$ $\leq 1.6$ ) was obtained in each deposition run, producing a composition range of $(0 \leq \mathrm{N} / \mathrm{Al} \leq 1.0)$ across each film. The film composition varied linearly with $N$ arrival flux and saturated at the composition of stoichiometric AlN with the rejection of excess $\mathrm{N}$. For stoichiometric films, the texture and microstructure depended strongly on the $\mathrm{N}_{2}{ }^{+}$ flux and ion energy. For low ion energies $(100 \mathrm{eV})$ and flux, the films formed with the $c$-axis perpendicular to the film surface, whereas for high ion beam energies $(500 \mathrm{eV})$ the $c$-axis was close to the plane of the film All films were polycrystalline. The AlN grain size increased with $\mathrm{N}_{2}{ }^{+}$ energy. The microstructure was found to be determined primarily by chemical driving forces, but was assisted by ion-enhanced diffusion and reaction.

Recently there has been a return to the use of CVDrelated techniques but with new reactant materials or with the introduction of plasma. Matloubian and Gershenzon [39] used trimethylaluminum (TMA), $\mathrm{NH}_{3}$, and (0001) sapphire and a substrate temperate range of $673-1473 \mathrm{~K}$. Monocrystalline AlN films were only obtained at 1473 K. Itoh et al. [40] deposited AlN films on graphite using RF (13.56 MHz) plasma-enhanced CVD (at 50-500 W) using mixtures of $\mathrm{AlBr}_{3}, \mathrm{~N}_{2}, \mathrm{H}_{2}$, and $\mathrm{Ar}$ and substrate temperatures in the range of $473-1073 \mathrm{~K}$. The deposition rate was strongly dependent on all these parameters as well as the linear flow velocity and the total pressure. Fine grained polycrystalline films were deposited at $973 \mathrm{~K}$ under a total pressure of $<10$ torr. Translucent polycrystalline AlN films having $<0001>$ preferred orientation were deposited in the range $15-40$ torr at the same temperature. Finally, Dryburgh [41] has obtained AIN via reaction between $\mathrm{Al}_{2} \mathrm{Se}$ and $\mathrm{N}_{2}$ in the temperature range $1815-1873 \mathrm{~K}$ using a unique CVD reactor. The orientations of sapphire were used as the substrates. Reaction between sapphire and $\mathrm{N}_{2}$ at $\mathrm{T}>1473 \mathrm{~K}$ caused roughening of the surface of the former and partial replacement of $\mathrm{Al}_{2} \mathrm{O}_{3}$ by $\mathrm{AlN}$.

Two major related problems with the use of sapphire for the growth of AlN are (a) the significantly different expansion coefficients and (b) the fact that the anisotropies in these coefficients for these two hexagonal crystals are in the opposite senses: for AIN, $\alpha_{\perp C}>\alpha_{\| C}$ while for $\mathrm{Al}_{2} \mathrm{O}_{3}, \alpha_{\perp C}<\alpha_{\| C}$. The poor results usually obtained in the attempts to grow smooth, monocrystalline layers of this material are thus explained. The same is true for $\mathrm{GaN}$, the material under discussion in the next subsection.

\section{Gallium Nitride}

Of all the III-V nitrides, GaN has been the most studied for optoelectronic applications. Films of $\mathrm{GaN}$ have been grown from the vapor phase by several techniques including low and high pressure CVD, plasma-enhanced CVD, reactive ionized-cluster beam deposition, and reactive and ionized molecular beam epitaxy. Reactive sputtering of gallium in $\mathrm{NH}_{3}, \mathrm{~N}_{2}-\mathrm{NH}_{3}$, or $\mathrm{N}_{2}$-Ar mixtures and solution growth from $\mathrm{Ga}$ or $\mathrm{Ga}-\mathrm{Bi}$ mixtures have been occasionally used to grow crystalline or amorphous films and small bulk crystals, respectively. Sapphire has been the most widely used substrate, although its lattice parameters and coefficients of thermal expansion are about $23 \%$ and about $25 \%$ greater, respectively, than those of GaN. Recently, films of cubic $\beta$ - and wafers of hexagonal $\alpha(6 \mathrm{H})-\mathrm{SiC}$ and $\mathrm{GaAs}$ single crystals have been employed as substrates. The potential applications of $\mathrm{GaN}$ include light emitting devices and UV emitting lasers, electrooptic, piezoelectric 
and acoustooptic modulators, and negative-electron affinity devices. Two reviews of the deposition methods and luminescent properties of this material have recently appeared [42], [43]. The reader is referred to these references and their bibliographies for a detailed and historical summary through 1988. The following summarizes selected portions of the research since that time.

The recent research regarding pure $\mathrm{GaN}$ has been concerned with four main aspects: (1) achievement of the cubic $\beta-\mathrm{GaN}$, (2) the use of unusual techniques to deposit the material at low $(<1300 \mathrm{~K})$ temperatures, $(3)$ the application of an AlN buffer layer between the substrate (usually sapphire) and the GaN film, and (4) the use of electron beams to achieve p-type material and p-n junctions.

The first reference to the apparent achievement of the cubic (zincblende structure) $\beta-\mathrm{GaN}$ is to the research of Mizuta et al. [44]. These investigators employed trimethylgallium and hydrazine, as the $\mathrm{Ga}$ and $\mathrm{N}$ sources, respectively, and GaAs (100) substrates. X-ray precession measurements indicated cubic $\mathrm{GaN}$; however, the diffracted intensity from the extremely thin film was very weak. Moreover, the RHEED data indicated the presence of the common hexagonal structure. Positive evidence for the growth of monocrystalline, epitaxial $\beta$-GaN has been reported by Paisley et al. [45]. This was achieved at 773-973 K using gas-source MBE with thermally evaporated $\mathrm{Ga}$ and atomic $\mathrm{N}$ and $\mathrm{N}_{2}{ }^{+}$derived from a microwave plasma source as the reactants and cubic $\beta$-SiC (100) as the substrate. Transmission electron microscopy studies showed the $170 \mathrm{~nm}$ films to be cubic and to contain threading dislocations and microtwins near the interface, the concentration of which decreased rapidly after $25 \mathrm{~nm}$ of growth. RHEED patterns confirmed the cubic nature of the films. Auger electron spectroscopy indicated a nominally stoichiometric GaN film. The lattice parameter and bandgap were determined to be $0.454 \mathrm{~nm}$ and $3.26 \mathrm{eV}$, respectively. More recently, two groups at the University of Illinois, namely Powell et al. [46] and Morkoc [47] have achieved $\beta-\mathrm{GaN}$ on $\mathrm{MgO}(100)$ and GaAs (100), respectively, using modified MBE techniques including an ion source and an electron cyclotron resonance plasma source to produce activated and ionized nitrogen. The material obtained by the former group had a lattice parameter and optical bandgap of $0.4531 \mathrm{~nm}$ and $3.30 \mathrm{eV}$, respectively. The electron carrier concentration also decreased from $4 \times 10^{18}$ to $8 \times 10^{13} / \mathrm{cm}^{3}$ with increasing $\mathrm{N}_{2}{ }^{+} / \mathrm{Ga}$ flux ratios between 0.63 and 3.9 which supports the common theory that the high donor concentrations are associated with $\mathrm{N}$ vacancies. Resistivities $>10^{6} \Omega \cdot \mathrm{cm}$ were achieved. The latter group [47] has conducted extensive TEM characterization of the cubic films. The lattice constant was reported to be $0.45 \mathrm{~nm}$. TEM revealed a high dislocation density in the GaN due to the large lattice mismatch which extended into the GaAs (probably due to the mismatch in coefficients of thermal expansion and the significant lattice resistance to dislocation motion in $\mathrm{GaN}$ at low temperatures). The electrical resistance exceeded $100 \Omega \cdot \mathrm{cm}$. The bandgap was reported to be $3.26 \mathrm{eV}$, in agreement with the results of Paisley et al. [45].
A plasma technique has also been employed by Humphreys et al. [48] to achieve $\mathrm{GaN}$ on (0001) $\mathrm{Al}_{2} \mathrm{O}_{3}$ substrates. Specifically, the procedure consisted of using a remote $\mathrm{He}$ gas discharge combined with the down-stream introduction of trimethylgallium and $\mathrm{N}_{2}$. Both cubic [111] and hexagonal [0001] polycrystalline films were obtained, but at different growth temperatures in the range of 673-973 $\mathrm{K}$. As in the previous studies, microtwinning as well as double positioning boundaries and dislocations were observed in high concentrations. The lattice parameter of the cubic phase was measured to be $0.450+0.002 \mathrm{~nm}$. Raman spectra were also obtained. Unfortunately this approach has not yet allowed a high resistivity material to be grown, as the electron carrier concentrations were in the $1.0-6.0 \times 10^{19} / \mathrm{cm}^{3}$ range.

Numerous substrate materials have been used for the deposition of GaN with the most common being (0001) sapphire. However, the surface morphology of these films markedly improved if an AlN buffer layer was initially deposited on the sapphire, as shown initially by Yoshida et al. [49], [50]. More recently Amano et al. [51] and Akasaki and coworkers [52] have shown that the use of the AlN layer reduces microscopic fluctuation in crystallite orientation, to relax the strain between sapphire and $\mathrm{GaN}$ and to promote lateral growth of the film due to the decrease in interfacial free energy between the film and the substrate. These investigators have used the positive effects of this layer to grow high quality $\mathrm{GaN}$ films in which to produce $\mathrm{p}-\mathrm{n}$ junctions and light-emitting diodes, as discussed below.

Khan et al. [53], [54] used a metalorganic (MO) CVD process similar to that of Akasaki and Amano but at 76 torr. The A1N buffer layer was 50-nm thick. They reported [53] electron carrier densisites as low as $1 \times 10^{17}$ with mobilities in excess of $300 \mathrm{~cm}^{2} / \mathrm{V} \cdot \mathrm{s}$ at room temperature. Photoluminescence linewidths as low as $25 \mathrm{meV}$ were achieved. In addition, they reported [54], for the first time, vertical cavity stimulated emission at room temperature from $1.5-\mu \mathrm{m}$ thick $\mathrm{GaN}$ layers. The gain coefficient was $\approx 10^{4} \mathrm{~cm}^{-1}$. This represents significant progress towards the achievement of a carrier injection type UV laser based on the $\mathrm{A} 1_{\mathrm{x}} \mathrm{Ga}_{1-{ }_{\mathrm{x}}} \mathrm{N}$ system.

Nearly all researchers who have grown $\mathrm{GaN}$ by CVD and other processes have also investigated in situ doping with $\mathrm{Zn}$ and $\mathrm{Mg}$. Both of these dopants as well as $\mathrm{Cd}, \mathrm{Be}$, $\mathrm{Ge}$, and $\mathrm{Si}$ compensate for the n-type character of $\mathrm{GaN}$, but until recently, none had been used successfully in the making of p-type GaN. However, electrical measurements following cathodoluminescence studies by Amano et al. [55], [56] showed that low-energy electron-beam irradiation of GaN films (LEEBI) produced distinct p-type conduction. The LEEBI exposure not only produced compensation for the n-type character but increased the p-type conductivity and enhanced the photoluminescence efficiency [55] of the material grown and doped by metal organic vapor phase epitaxy. The hole concentrating and mobility and the resistivity at $293 \mathrm{~K}$ were $2 \times 10^{16} \mathrm{~cm}^{-3}, 8 \mathrm{~cm}^{2} / \mathrm{V} \cdot \mathrm{s}$ and $35 \Omega \cdot \mathrm{cm}$, respectively. The best $\mathrm{GaN}$ was deposited at $1310 \mathrm{~K}$ on a $50 \mathrm{~nm}$ AlN buffer layer previously deposited on sapphire at 
$873 \mathrm{~K}$. The $\mathrm{Mg}$ atomic concentration was $\approx 10^{20} / \mathrm{cm}^{3}$. The crystal chemical mechanism for this phenomenon has not been discerned. As a result of this work, these researchers have fabricated a p-n junction LED which showed strong near-band edge emission due to hole injection from the player into the n-layer at room temperature. Finally, Akasaki and coworkers have reported near ultraviolet stimulated emission from a $\mathrm{GaN}$ film [57] at room temperature. These results indicate the increasing likelihood of a current injection UV laser diode in the near future. In other research Khan [58] has indicated that he has also achieved p-type GaN using a self-limiting atomic layer epitaxy process and the primary reactants of triethylgallium and amonia and trimethylzinc as the dopant.

Although a solution to fabricating p-type films has been discovered, they must be deposited on highly mismatched substrates or intermediate layers. These films, as well as those deposited on $\beta$-SiC and $\mathrm{GaAs}$, are highly defective in terms of dislocations and stacking faults. The ideal substrate would be $\mathrm{GaN}$, but bulk monocrystalline $\mathrm{GaN}$ does not exist despite several attempts with different growth methods. These problems will very likely inhibit the development of GaN-based electronic devices for high power and high frequency applications. Moreover, suitable ohmic and rectifying contacts for $\mathrm{n}$ - and $\mathrm{p}$-type $\mathrm{GaN}$ do not exist; insulating field and gate materials must be developed for GaN devices, as there is no stable native oxide of Ga. Etchants and etching procedures have not been developed for $\mathrm{GaN}$.

\section{AlN/GaN Solid Solutions and Heterostructures}

Solid solutions of AlN and GaN have been produced by several methods to achieve bandgap engineering by analogy with the $\mathrm{Al}_{\mathrm{x}} \mathrm{Ga}_{1-\mathrm{x}} \mathrm{X}(\mathrm{X}=\mathrm{Sb}$, As, and $\mathrm{P})$ systems. The $\mathrm{Al}_{\mathrm{x}} \mathrm{Ga}_{1-\mathrm{x}} \mathrm{N}$ solutions have the potential for optoelectronic devices operating in the ultraviolet as a result of the direct gaps between 3.45 and $6.28 \mathrm{eV}$. Baranov et al. [59] and Hagen et al. [60] were the first to fabricate films of these materials via chloride vapor phase epitaxy. The former group produced films to $x=0.45$ at $1325 \mathrm{~K}$. The latter investigators showed the existence of complete solid solubility throughout the binary system. This research set in motion a semicontinuous exploration of these materials, primarily in Japan and the United States which is still ongoing.

Yoshida and coworkers [61], a collaborative effort between Khan et al. and Gershenzon [62] and the individual efforts of Gershenzon and his students [63] were the next research teams to produce and characterize these solid solutions. Yoshida et al. produced single crystal films over the entire composition range on (0001) sapphire and (111) $\mathrm{Si}$ at $973 \mathrm{~K}$ by RMBE using evaporated $\mathrm{Ga}$ and $\mathrm{Al}$ and $\mathrm{NH}_{3}$. The variations in lattice constant, electrical properties, energy gap and the energy of the intense peak in the cathodoluminescence spectra are shown in Figs. 7-10. A perusal of these figures show that the lattice constant exhibits a nonlinear dependence on composition. By contrast, the bandgap energy and the cathodoluminescence peaks vary smoothly throughout the compositional range. Similar

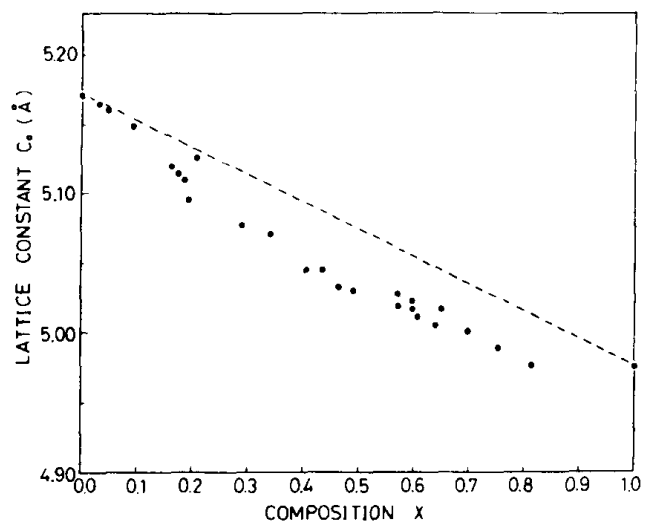

Fig. 7. Variation of the lattice constant $c_{0}$ with the alloy composition $x$ of $\mathrm{Al}_{\mathrm{x}} \mathrm{Ga}_{1-\mathrm{x}} \mathrm{N}$ films [61].

but less extensive research has been conducted by Khan et al. using triethylgallium, trimethylaluminum (TMA), $\mathrm{NH}_{3}$ and (0001) sapphire substrates held at a temperature of $1190 \mathrm{~K}$. In contrast to Yoshida, they found that the carrier mobility and the carrier concentration decreased with increasing values of $\mathrm{Al}$ concentration. However, a linear dependence of the bandgap energy with composition was also found thus indicating (as did Yoshida's results) that the bowing parameter is small. This conclusion has been refuted by Koide et al. [64] who later reported that the energy gap in the range $0<\mathrm{X} \leq 0.4$ AlN does not change linearly but bows downward with increasing AlN. Samples with $\mathrm{AlN}>$ at $\% 40 \%$ were highly resistive even at room temperature. Of particular interest was the implantation of pure $\mathrm{GaN}$ and $\mathrm{Al}_{0.2} \mathrm{Ga}_{0.18} \mathrm{~N}$ with $\mathrm{Be}^{+}$and $\mathrm{N}^{+}$implants on separate sample areas. Compensation of the n-type material was achieved and Cr/Au Schottky contacts were deposited onto the implanted regions. Rectifying characteristics for $\mathrm{N}^{+}$implants in the alloy were reported with moderate leakage current in reverse bias. Finally, in a related study, Sayyah et al. [63] using TMG, TMA, and $\mathrm{NH}_{3}$ in a $\mathrm{H}_{2} \mathrm{O}$-cooled reactor found that the incorporation rates of both $\mathrm{Ga}$ and $\mathrm{Al}$ in the growing film decreased rapidly with the substrate temperature above $1173 \mathrm{~K}$ with the incorporation rates of $\mathrm{Ga}$ dropping faster than $\mathrm{Al}$. These results were postulated to be caused by the decrease in surface adsorption with the more rapid desorption of $\mathrm{Ga}$ relative to $\mathrm{Al}$.

Quantum well structures consisting of $0.2 \mu \mathrm{m}$ layers of $\mathrm{A1}_{0.14} \mathrm{Ga}_{0.86} \mathrm{~N}$ surrounding the $\mathrm{GaN}$ well $(10-30 \mathrm{~nm})$ have been produced by Khan et al. [65]. This assembly was also deposited via MOCVD on an A1N buffer layer previously deposited on sapphire at $1273 \mathrm{~K}$. The photoluminescence spectra of samples having different well thicknesses were measured and compared to theoretical solutions for the quantum well. The difference between peak emission from $\mathrm{GaN}$ bulk and quantum well structures consisted of a large constant offset $(35.5 \mathrm{meV})$ and a smaller shift due to quantum size effects. The magnitude of the constant offset 


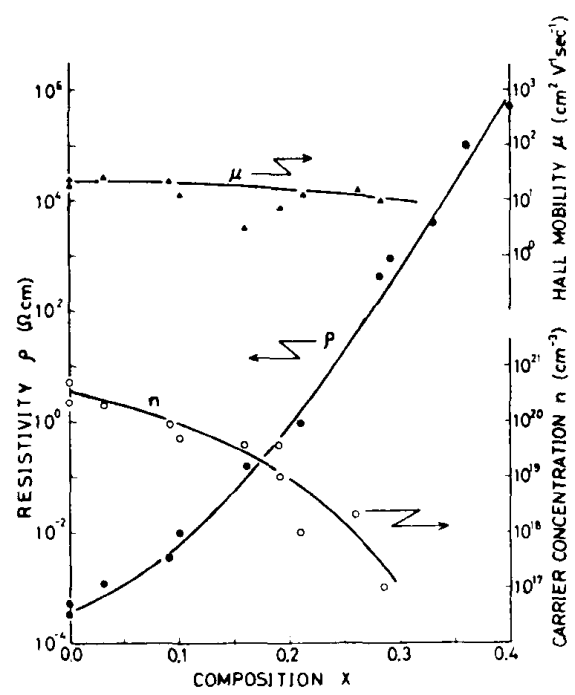

Fig. 8. Composition dependence of the resistivity $\rho$, the carrier concentration $n$, and the Hall mobility $\mu$ at room temperature [61].

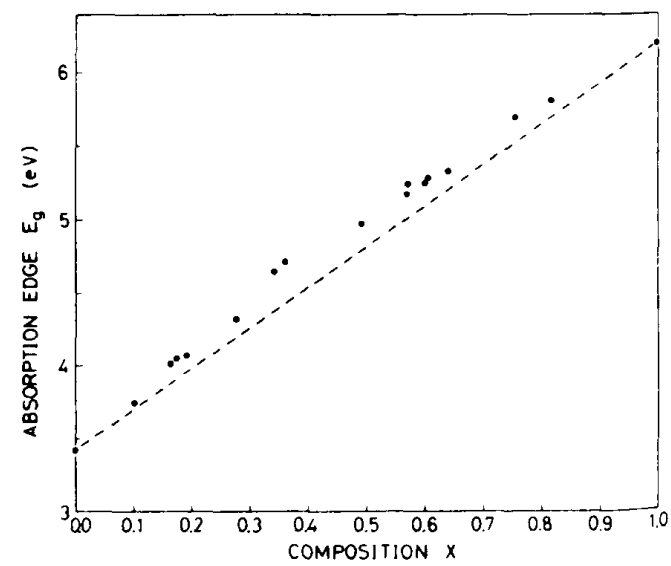

Fig. 9. Composition dependence of the direct energy gap $\mathrm{Eg}$ of $\mathrm{Al}_{\mathrm{x}} \mathrm{Ga}_{1-\mathrm{x}}$ $N$ alloys $[61]$

is consistent with the disappearance of band tails in the well and/or strain-induced band shifts due to the lattice mismatch between $\mathrm{A} 1 \mathrm{GaN}$ and $\mathrm{GaN}$.

In a related study, Khan et al. [66] have reported a substantial increase in mobility in single $\mathrm{GaN}(300$ $\mathrm{nm}) / \mathrm{A}_{0.15} \mathrm{Ga}_{0.85} \mathrm{~N}(50 \mathrm{~nm})$ heterojunctions $\left(1155 \mathrm{~cm}^{2} / \mathrm{V} \cdot \mathrm{s}\right.$ $(23 \mathrm{~K})$ and $460 \mathrm{~cm}^{2} / \mathrm{V} \cdot \mathrm{s}(77 \mathrm{~K})$ ) relative to bulk GaN (56 $\mathrm{cm}^{2} / \mathrm{V} \cdot \mathrm{s}(23 \mathrm{~K})$ and $\left.19 \mathrm{~cm}^{2} / \mathrm{V} \cdot \mathrm{s}(77 \mathrm{~K})\right)$, again produced via MOCVD using sapphire coated with $A 1 N$. The high mobility values were attributed primarily to the presence of a two-dimensional electron gas at the interface similar to that reported for $\mathrm{GaAs} / \mathrm{A}_{\mathrm{x}} \mathrm{Ga}_{1-\mathrm{x}}$ As heterojunctions [67]. The band discontinuity was estimated to be $0.25 \mathrm{eV}$. Evidence for the presence of the two-dimensional electron gas was obtained from a multiple (18) heterojunction structure. The mobility in this structure increased more than two-fold relative to a two-layer assembly.

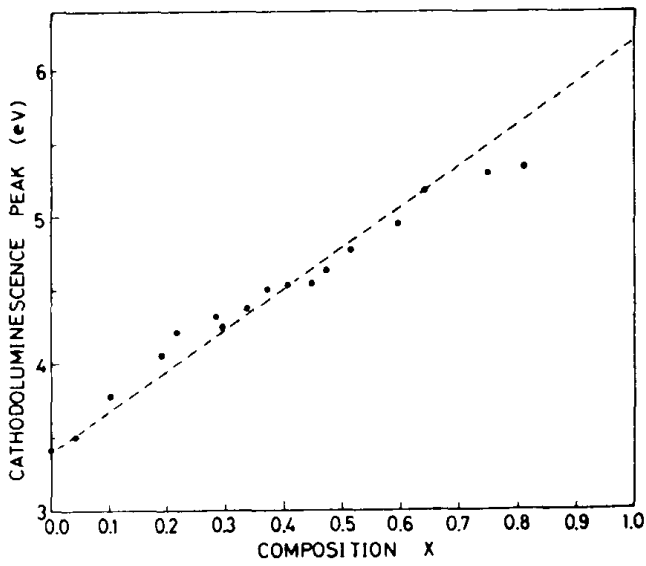

Fig. 10. Composition dependence of the energy of the intense peak of cathoduluminescence spectra in the ultraviolet [61].

Heterostructures of AIN and GaN have been fabricated by Yoshida et al. [49], [50] and Sitar and coworkers [68]. In the research of the former group, $(0001) \mathrm{GaN}$ was deposited directly on (0001) sapphire or, as noted above, on $\approx 300$ $\mathrm{nm}$ of (0001) AlN previously deposited on sapphire. The substrate temperatures for all depositions of AIN and GaN were $1373 \mathrm{~K}$ and $973 \mathrm{~K}$, respectively. The GaN deposited on the AlN showed a three-fold increase in Hall mobility to $\approx 34 \mathrm{~cm}^{2} / \mathrm{V} \cdot \mathrm{s}$ which was independent of the film thickness. Moreover, the $\mathrm{GaN}$ cathodoluminesence peak at $360 \mathrm{~nm}$ (valence band-to-conduction band transition) was sharper and much more intense for the material deposited on the AIN. This intensity increased with an increase in thickness of the GaN, especially beyond $0.2-0.4 \mu \mathrm{m}$ for all films due to the enhanced quality of the films. A decrease in the luminesence intensity was noted when the thickness of the AIN layer was less than $200 \mathrm{~nm}$.

Multiple AlN/GaN bilayer heterostructures having individual periods of $1.5-40 \mathrm{~nm}$ and total numbers of periods per deposition of 20-200 have been grown at NCSU on (0001)-oriented sapphire and $\alpha(6 \mathrm{H})$-SiC substrates containing a $140 \mathrm{~nm} \mathrm{GaN}$ buffer layer within the temperature range of 773-1025 K using gas source MBE in the ionized mode [68]. Standard effusion cells were used as sources of $\mathrm{Al}$ and Ga. An MBE compatible, electron cyclotron resonance (ECR) plasma source produced activated/ionized nitrogen prior to deposition. Auger, X-ray diffractometry, and TEM analyses showed the interfaces to be compositionally, structurally, and microstructurally sharp. Figure 11 shows a TEM image of 5-nm thick layers of each compound. The $(10 \overline{1} 1)$ diffraction pattern (inset), taken only from the layered structure confirms the monocrystalline nature of this assembly. Coherent interfaces (no relaxation by misfit dislocations) were observed for bilayer periods less than $6 \mathrm{~nm}$. By contrast, completely relaxed individual layers of GaN and AIN with respect to each other were present for bilayer periods above $20 \mathrm{~nm}$. Cathodoluminesence revealed a shift in the position of the principal emission 


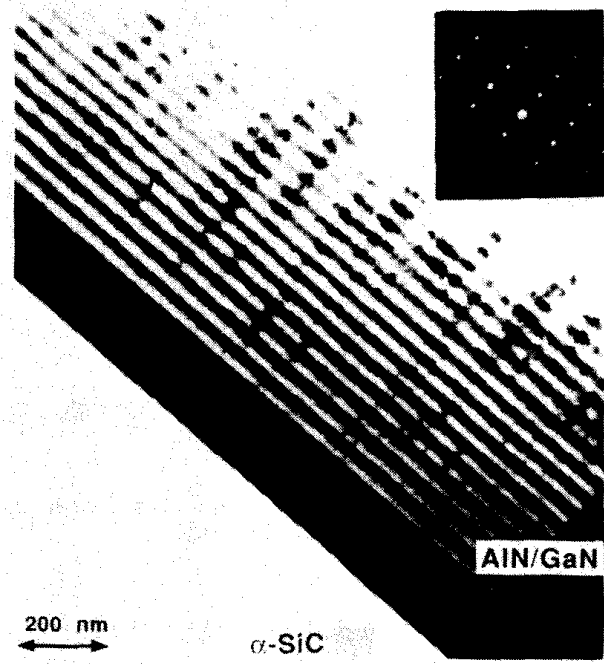

Fig. 11. AIN (light)/GaN (dark) layered heterostructure grown on $\alpha(6 \mathrm{H})-\mathrm{SiC}$. The thickness of the individual layers is $20 \mathrm{~nm}$ [68].

peak from $3.42 \mathrm{eV}$ for the sample with individual $10-\mathrm{nm}$ thick GaN layers to $4.11 \mathrm{eV}$ for the sample having $1-\mathrm{nm}$ thick individual layers. These last results are believed to be caused by quantum size effects. There also exists a constant offset of $170 \mathrm{meV}$ between the experimental and calculated values. Since this offset is present only for the pseudomorphic structures, it has been related to the strain induced bandgap shift of the two materials.

\section{E. Indium Nitride}

Of all the III-V nitride compounds, InN has been the least studied. All the aforementioned problems associated with $\mathrm{GaN}$, i.e., high equilibrium $\mathrm{N}_{2}$ vapor pressure, high electron carrier concentration and low mobility are found in InN [69]. As in the case of $\mathrm{GaN}$, the poor semiconducting properties have been associated with the presence of $\mathrm{N}$ vacancies and therefore the high vapor pressure of this component. (The argument of self-compensation to explain the lack of p-type character in InN and $\mathrm{GaN}$ has never been used even though it apparently accounts for this phenomenon in $\mathrm{ZnO}$ and $\mathrm{ZnSe}$.). As such, several low temperature film deposition methods have been employed over the years with varying results.

Hovel and Cuomo [70] were apparently the first to reactively $\mathrm{RF}$ sputter $\mathrm{InN}$. They employed an In target, pure $\mathrm{N}_{2}$ and (0001) sapphire and (111) Si heated in the range of $300-873 \mathrm{~K}$. The resulting films were polycrystalline, preferentially oriented and highly conducting n-type with an electron concentration of $7 \times 10^{18} \mathrm{~cm}^{-3}$ and a Hall mobility of $250 \pm 50 \mathrm{~cm}^{2} / \mathrm{V} \cdot \mathrm{s}\left(\rho=(3-5) \times 10^{-3} \Omega \cdot \mathrm{cm}\right)$. The achievement of InN films at $\mathrm{T}=873 \mathrm{~K}$ is proof that although the equilibrium vapor pressure of $\mathrm{N}_{2}$ is extreme, that of atomic nitrogen is much more moderate and can be used to successfully grow InN (and probably all other III-V nitrides) at higher than expected substrate temperatures. Extensive characterization of the reactive sputtering process of $\mathrm{InN}$ and related materials has been conducted by Natarajan et $a l$. [71]. In additional reactive sputtering research, Tansley and Foley [72] have reported a direct correlation between fully nitrided targets and high electron mobilities (and low electron concentrations). These authors have reported the most favorable data to date for these parameters $(\mu=3000$ $\mathrm{cm}^{2} / \mathrm{V} \cdot \mathrm{s}$ and $\left.\mathrm{n}=(2-10) \times 10^{16} \mathrm{~cm}^{-3}\right)$. However, sputtering from an incompletely nitrided target produced films with lower mobilities and higher $n$ values $\left(>10^{17} \mathrm{~cm}^{-3}\right)$. This relationship between poorly nitrided targets and higher electron concentrations has been apparently confirmed in research by Sullivan et al. [73].

Electron beam evaporation of In, a pulsed nitrogen plasma and (0001) sapphire substrates at $T=300-650 \mathrm{~K}$ have been used by Trainor and Rose [74]. Typical growth rates ranged from $1.0-1.2 \mu \mathrm{m} / \mathrm{h}$. The best material had a Hall mobility at $300 \mathrm{~K}$ of $20 \mathrm{~cm}^{2} / \mathrm{V} \cdot \mathrm{s}$ and a carrier concentration in the $10^{20} \mathrm{~cm}^{-3}$ range. These electronic results are similar to those of Marasina et al. [75] who employed the interaction of $\mathrm{InCl}_{3}$ and $\mathrm{NH}_{3}$ on (0001) sapphire. The former authors also found that annealing $\mathrm{InN}$ in $\mathrm{N}_{2}$ at $773 \mathrm{~K}$ caused rapid decomposition; however, this did not occur even within an hour at $10^{-3}$ torr in the presence of atomic nitrogen. Similar research has more recently been conducted by Masaki et al. [76]. Their primary alteration was the use of an ion gun instead of a direct plasma to provide the reactive nitrogen species. Silicon and glass were additional substrate choices. The films were deposited at room temperature; however, In- $\mathrm{N}$ bonding was observed by infrared absorption only after heating the deposited film to $450 \mathrm{~K}$. Defects and/or impurities dominated the electrical characteristics, especially at and below room temperature.

\section{SUMMARY}

The potential of III-V nitride thin films for applications in high-power and high-frequency electronic devices and optoelectronic devices over a broad range of wavelengths is considerable-but this has been recognized for many years without truly viable materials or devices being produced. The lack of a suitable substrate, with the possible exception of $\mathrm{SiC}$ for $\mathrm{AlN}$, is a problem of considerable magnitude. This is compounded by the presence of shallow donor bands in $\mathrm{GaN}$ and $\mathrm{InN}$ which are apparently caused by $\mathrm{N}$ vacancies. The question of whether these vacancies occur (if they do) as a result of intrinsic or extrinsic (as a result of deposition) nonstoichiometry has not been answered. The recent advances of Akasaki and his coworkers [55]-[57] in the fabrication of p-type $\mathrm{GaN}$ and a $\mathrm{p}$-n junction light emitting diode via the electron beam stimulation of the $\mathrm{Mg}$ dopant is very encouraging and may considerably advance the technology of this material. This would indicate that self-compensation effects, similar to those observed in $\mathrm{ZnO}$ and $\mathrm{ZnSe}$, may not be present in the III- $\mathrm{V}$ nitrides, 
since cBN, AlN, and now GaN have been reportedly doped both $\mathrm{n}$ - and p-type. It is also encouraging that several routes to lower temperature processes have been successful. However, if the number of workers in the field continues to be small, the commercial reality of devices from these materials, individually, as solid solutions and/or as heterostructures may be several years away.

\section{ACKNOWLEDGMENT}

Deepest appreciation is expressed to Z. Sitar and M. Paisley who contributed to this manuscript.

\section{REFERENCES}

[1] Wentorf, R. H. Jr., "Synthesis of cubic form of boron nitride," J. Chem. Phys. vol. 36, pp. 1990-1998, Mar. 1961.

[2] R. C. Devries, "Cubic boron nitride: Handbook of properties," Tech. Rep. 72 CRD178, General Electric Company, Schenectady, NY 12301, pp. 1-17, June 1972.

[3] M. Sokolowski, "Deposition of wurtzite type boron nitride layers by reactive pulse plasma crystallization," $J$. Cryst. Growth, vol. 46, pp. 136-138, Jan. 1979

[4] H-J. Erler, G. Reisse, and C. Weissmantel, "Nitride film deposition by reactive ion beam sputtering," Thin Solid Films, vol. 65 , pp. 233-245, Jan. 15, 1980.

[5] C. Weissmantel, "Ion beam deposition of special film structures," J. Vac. Sci. Technol., vol. 18, pp. 179-185, Mar. 1981.

[6] C. Weissmantel, K. Bewilgova, K. Bruer, D. Dietrich, U Ebersbach, H-J. Erler, B. Rau, and G. Reisse, "Preparation and properties of hard i-C and i-BN coatings," Thin Solid Films, vol. 96, pp. 31-38, 1982.

[7] S. Shanfield, and R. Wolfson, "Ion beam synthesis of cubic boron nitride," J. Vac. Sci. Technol. A, vol. 1, pp. 323-332, Apr.-June 1983.

[8] M. Satou and F. Fujimoto, "Formation of cubic boron nitride films by boron evaporation and nitrogen ion beam bombardment," Japan. J. Appl. Phys., vol. 22, pp. L171-L172, Mar. 1983 .

[9] K. L. Chopra, V. Agrawal, V. D. Vankar, C. V. Deshpandey, and R. F. Bunshah, "Synthesis of cubic boron nitrite films by activated reactive evaporation of $\mathrm{H}_{3} \mathrm{BO}_{3}$," Thin Solid Films, vol. 126 , pp. 307-315, 1985.

[10] P. Lin, C. Deshpandey, H. J. Doerr, R. F. Bunshah, K. L Chopra, and V. D. Vankar, "Preparation and properties of cubic boron nitride coatings," Thin Solid Films, vol. 152, pp. 487-496, 1987.

[11] K. Inagawa, K. Watanabe, H. Ohsone, K. Saitoh, and A. Itoh, "Preparation of cubic boron nitride film by activated reactive evaporation," J. Vac. Sci. Technol. A, vol, 5, pp. 2696-2702, July/Aug. 1987.

[12] T. Ikeda, Y. Kawate, and Y. Hirai, "Formation of cBN films by arc-like plasma-enhanced ion plating method," Kobelco Technol. Rev., vol. 6, pp. 1-4, Aug. 1989 .

[13] H. D. Wiggins, C. R. Aita, and F. S. Hickernell, "Radio frequency sputter deposited boron nitride films," J. Vac. Sci. Technol., vol. A2, pp. 322-325, Apr.-June 1984.

[14] K. H. Seidel, K. Reichelt, W. Schaal, and H. Dimigen, "The preparation of cubic boron nitride films by reactive diode sputtering," Thin Solid Films, vol. 156, pp. 215-230, 1987.

[15] S. P. S. Arya and A. D'Amico, "Preparation, properties and applications of boron nitride thin films," Thin Solid Films, vol. 157 , pp. 267-282, Feb. 29, 1988 .

[16] G. L. Doll, J. A. Sell, L. Salamanca-Riba, and A. K. Bullal, "Laser deposited cubic boron nitride films," Appl. Phys. Lett., to be published.

[17] O. Mishima, J. Tanaka, S. Yamaoaka, and O. Fukunaga, "Hightemperature cubic boron nitride p-n junction diode made at high pressure," Science, vol. 238, pp. 181-186, Feb. 1987

[18] O. Mishima, K. Era, J. Tanaka, and S. Yamaoka, "Ultraviolet light-emitting diode of a cubic boron nitride $\mathrm{p}-\mathrm{n}$ junction made at high pressure," Appl. Phys. Lett., vol. 53, pp. 962-964, July 1988 , and private discussions.

[19] W. M. Yim, E. J. Stofko, P. J. Zanzucchi, J. I. Pankove, M Ettenberg, and S. L. Gilbert, "Epitaxially grown AIN and its optical bandgap," J. Appl. Phys., vol. 44, pp. 292-296, Jan. 1973.

[20] Y. Fujii, S. Yoshida, S. Misawa, S. Maekawa, and T. Sakudo, "Nonlinear Optical Susceptibilities of AlN film," Appl. Phys. Lett., vol. 31, pp. 815-817, Dec. 15, 1977.

[21] G. R. Kline, and K. M. Lakin, "Composite thin film UHF bulk acoustic wave resonators on gallium arsenide," in Proc. IEEE Symp. Ultrasonics, vol. 14, pp. 495-453, 1983.

[22] M. Kitayama, T. Fukui, T. Shiosaki, and A. Kawabata, "VHF/UHF composite resonator on a silicon substrate," Japan. J. Appl. Phys., pt. 1, vol. 22 (supplement 22-23), pp. 139-143, Jan. 1982.

[23] K. Tsubouchi, K. Sugai, and Mikoshiba "Zero temperature coefficient surface-acoustic-wave devices using epitaxial aluminum nitride films," in Proc. IEEE Symp. Ultrasonics, vol. 14, pp. $340-346,1983$.

[24] M. Sano and M. Aoki, "Properties of III-V nitride semiconductors," Oyo Butsuri, vol. 52, pp. 374-376, June 1983, in Japanese.

[25] M. G. Norton, B. C. H. Steele, and C. A. Leach, "Characterisation and metallisation of AlN ceramics," Science of Ceramics, vol. 14, pp. 545-550, Sept. 1988.

[26] L. Cartz, F. G. Karioris, and R. A. Fournelle, "Heavy ion bombardment of silicates and nitrides," Rad. Effects, vol. 54, pp. 57-64, 1981.

[27] M. Morita, S. Isogai, N. Shimizu, K. Tsubouchi, and N. Mikoshiba, "Aluminum nitride epitaxially grown on silicon: orientation relationships," Japan. J. Appl. Phys., vol. 20, pp. L173-L175, Mar. 1981.

[28] M. T. Duffy in Heteroepitaxial Semiconductors for Electronic Devices, G. W. Cullen and C. C. Wang, Eds. New York: Springer-Verlag, pp. 150-181, 1978.

[29] G. A. Cox, D. O. Cummins, K. Kawabe, and T. Tredgold, On the preparation, optical properties and electrical behavior of an aluminum nitride," J. Phys. Chem. Solids, vol. 28, pp. 543-551, Apr. 1967.

[30] T. L. Chu, D. W. Ing, and A. J. Noreika, "Epitaxial growth of aluminum nitride," Solid-State Electron., vol. 10, pp. 1023-1027, Oct. 1967.

[31] A. J. Noreika and D. W. Ing, "Growth characteristics of AIN films pyrolytically deposited on Si," J. Appl. Phys., vol. 39, pp. 5578-5584, Nov. 1968 .

[32] H. M. Manasevit, F. M. Erdmann, and W. I. Simpson, "The use of metalorganics in the preparation of semiconductor materials," J. Electrochem. Soc., vol. 118, pp. 1864-1868, 1971.

[33] M. T. Duffy, C. C. Wang, G. D. O'Clock, Jr., S. H. McFarlane III, and P. J. Zanzucchi, "Epitaxial growth and piezoelectric properties of aluminum nitride and gallium arsenide on sapphire or spinel," J. Electron. Mater., vol. 2, pp. 359-370, 1973.

[34] K. M. Lakin, L. Liu, and K. Wang, "Aluminum nitride on sapphire," in Proc. Ultrasonics Symp., 1974, pp. 302-325.

[35] M. P. Callaghan, E. Patterson, B. P. Richards, and C. A. Wallace, "The growth, crystallographic and electrical assessment of epitaxial layers of aluminum nitride on corundium substrates," J. Cryst. Growth, vol. 22, pp. 85-98, Apr. 1974.

[36] F. A. Pizzarello and J. E. Coker, "The structural and piezoelectric properties of epitaxial $\mathrm{AlN}$ on $\mathrm{Al}_{2} \mathrm{O}_{3}$,"J. Electron. Mater. vol. 4, pp. 25-36, Feb. 1975.

[37] J. K. Liu, K. M. Lakin, and K. L. Wang, "Growth morphology and surface-acoustic wave measurements of AIN on sapphire," J. Appl. Phys., vol. 46, pp. 3703-3706, Sept. 1975.

[38] J. M. E. Harper, J. J. Cuomo, and H. T. G. Hentzell, "Synthesis of compound thin films by dual ion beam deposition I: Experimental Approach; II: Properties of aluminum-nitrogen films," J. Appl. Phys., vol. 58, pp. 550-560, July 1985.

[39] M. Matloubian and M. Gershenzon, "MOCVD epitaxial growth of single crystal GaN, AIN and $\mathrm{Al}_{\mathrm{x}} \mathrm{Ga}_{1-\mathrm{x}} \mathrm{N}$, , J. Electron. Mater., vol. 14 , pp. $633-644$, Sept. 1985 .

[40] H. Itoh, M. Kato and K. Sugiyama, "Plasma-enhanced chemical vapor deposition of AlN coatings on graphite substrates," Thin Solid Films, vol. 146, pp. 255-264, 1987.

[41] P. M. Dryburgh, "Factors affecting the growth of aluminum nitride layers on sapphire by the reaction of nitrogen with aluminum maroselenide," J. Crystal Growth, vol. 94, pp. 23-33, Jan. 1989

[42] R. F. Davis, Z. Sitar, B. E. Williams, H. S. Kong, H. J. Kim, J. W. Palmour, J. A. Edmond, J. Ryu, J. T. Glass, and C. H. Carter, Jr., "Critical evaluation of the status of the areas for 
future research regarding the wide band gap semiconductors diamond, gallium nitride and silicon carbide," Materials Science and Engineering B, vol. 1, pp. 77-104, July 1988 .

[43] J. I. Pancove, "Perspective on gallium nitride," in Materials Research Soc. Symp. Proc., vol, 116, J. T. Glass, R. F. Messier, and N. Fujimori, Eds. Pittsburgh, PA: Materials Research Society, 1990, pp. 515-524.

[44] M. Mizuta, S. Fujieda, Y. Matsumoto, and T. Kawamara "Low temperature growth of GaN and AIN on GaAs utilizing metalorganics and hydrazine," Japan. J. Appl. Phys., vol. 25, pp. L945-L948, Dec. 1986.

[45] M. J. Paisley, Z. Sitar, J. B. Posthill, and R. F. Davis, "Growth of cubic phase gallium nitride by modified molecular beam epitaxy,"J. Vac. Sci. Technol. A, vol. 7, pp. 701-704, Apr. 1989

[46] R. C. Powell, G. A. Tomasch, Y.-W. Kim, J. A. Thornton, and J. E. Greene, "Growth of high-resistivity wurtzite and zincblende structure single crystal GaN by reactive-ion molecular beam epitaxy," in Materials Research Soc. Symp. Proc., vol. 162, J. T. Glass, R. F. Messier, and N. Fujimori, Eds. Pittsburgh, PA: Materials Research Society, 1990, pp. 525-530.

[47] H. Morkoc, private communication

[48] T. P. Humphreys, C. A. Sukow, R. J. Nemanich, J. B. Posthill, R. A. Rudder, S. V. Hattangady, and R. J. Markunas, "Microstructural and optical characterization of GaN films grown by PECVD on (0001) sapphire substrates," in Materials Research Soc. Symp. Proc., vol. 162, J. T. Glass, R. F. Messier, and N. Fujimori, Eds. Pittsburgh, PA: Materials Research Society 1990, pp. 531-536.

[49] S. Yoshida, S. Misawa, and S. Gonda, "Improvements on the electrical and luminescent properties of reactive molecular beam epitaxially grown GaN films by using AlN-coated sapphire substrates," Appl. Phys. Lett., vol. 42, pp. 427-429, Mar. 1983.

[50] S. Yoshida, S. Misawa, and S. Gonda, "Epitaxial growth of GaN/AIN heterostructures," J. Vac. Sci. Technol. B, vol. 1, pp. 250-253, Mar. 1983.

[51] H. Amano, N. Sawaki, I. Akasaki, and Y. Toyoda, "Metalorganic vapor phase epitaxial growth of a high quality $\mathrm{GaN}$ film using an AIN buffer layer," Appl. Phys. Lett., vol. 48, pp. 353-355, Feb. 1986.

[52] I. Akasaki, H. Amano, Y. Koide, K. Hiramatsu, and N. Sawaki, "Effects of buffer layer on crystallographic structure and on electrical and optical properties of $\mathrm{GaN}$ and $\mathrm{Ga}_{1-\mathrm{x}} \mathrm{Al}_{\mathrm{x}} \mathrm{N}$ $(0 \leq \mathrm{x} \leq 0.4)$ films grown on sapphire substrate by MOVPE," $J$ Cryst. Growth, vol. 98, pp. 209-219, Mar. 1989

[53] M. A. Khan, J. N. Kuznia, J. M. Van Hove, D. T. Olson S. Krishnankutty, and R. M. Kolbas, "Growth of high optical and electrical quality GaN layers using low pressure matalorganic chemical vapor deposition," Appl. Phy. Lett., vol. 58, pp. 526-527, 1991

[54] M. A. Khan, D. T. Olson, J. M. Van Hove, and J. N. Kuznia, "Vertical cavity room temperature stimulated emission from photopumped GaN films deposited over sapphire substrates using low pressure metalorganic chemical vapor deposition," Appl. Phys. Lett., vol. 58, pp. 1515-1517, Apr. 1991.

[55] H. Amano, M. Kito, K. Hiramatsu, and I. Akasaki, "P-type conduction in $\mathrm{Mg}$-doped $\mathrm{GaN}$ treated with low-energy electronbeam irradiation (LEEBI)," Japan. J. Appl. Phys., vol. 28, pp. L.2112-L2114, Dec. 1989.

[56] H. Amano, I. Akasaki, T. Kozawa, K. Hiramatsu, N. Sawaki, $\mathrm{K}$. Ikeda, and Y. Ishii, "Electron beam effects on blue luminescence in Zn-doped GaN," J. Lumin., vols. 40 and 41, pp. 121-122, 1988.

[57] H. Amano, T. Asahi, and I. Akasaki, "Stimulated emission from a GaN film," Japan. J. App. Phys. Lett., vol. 28, pp. L150-L163, Feb. 1990.

[58] A. Kahn, APA Optics, Inc., private communication.

[59] B. Baranov, L. Daweritz, V. B. Gutan, G. Jungk, H. Neumann, and H. Raidt, "Growth and properties of $\mathrm{Ga}_{x} \mathrm{Al}_{1-x} \mathrm{~N}$ epitaxial layers," Phys. Status Solidi A, vol. 49, pp. L143-L146, Oct. 1978.
[60] J. Hagen, R. D. Metcalfe, D. Wickenden, and W. Clark, "Growth and properties of $\mathrm{Ga}_{\mathrm{x}} \mathrm{Al}_{1-\mathrm{x}} \mathrm{N}$ compounds", J. Phys. C, vol. 11, pp. L143-L148, Feb. 1978.

[61] S. Yoshida, S. Misawa, and S. Gonda, "Properties of $\mathrm{Al}_{x} \mathrm{Ga}_{1-x} \mathrm{~N}$ films prepared by reactive molecular beam epitaxy," J. Appl. Phys., vol. 53, pp. 6844-6848, Oct. 1982.

[62] M. A. Khan, R. A. Skogman, R. G. Schulze, and M. Gershenzon, "Electrical properties and ion implantation of epitaxial GaN, grown by low pressure metalorganic chemical vapor deposition," Appl. Phys. Lett., vol. 42, pp. 430-432, Mar. 1983.

[63] K. Sayyah, B. Chung, and M. Gershenzon, "The influence of TMA and $\mathrm{SiH}_{4}$ on the incorporation rate of $\mathrm{Ga}$ in $\mathrm{Al}_{x} \mathrm{Ga}_{1-\mathrm{x}} \mathrm{N}$ crystals grown from TMG and $\mathrm{NH}_{3}$, , J. Cryst. Growth, vol. 77, pp. $424-429$, Sept. 1986.

[64] Y. Koide, H. Itoh, M. R. H. Khan, K. Hiramatu, N. Sawaki, and I. Akasaki, "Energy band-gap bowing parameter in an $\mathrm{Al}_{\mathrm{x}} \mathrm{Ga}_{1-\mathrm{x}} \mathrm{N}$ alloy," J. Appl. Phys., vol. 61, pp. 4540-4543, May 1987.

[65] M. A. Khan, R. A. Skogman, J. M. Van Hove, S. Krishnankutty, and R. M. Kolbas, "Photoluminescence characteristics of A1GaN-GaN-A1GaN quantum wells," Appl. Phys. Lett., vol. 56, pp. 1257-1259, Mar. 1990.

[66] Y. M. A. Khan, J. M. Van Hove, J. N. Kuznia, and D. T. Olson, "High electron mobility $\mathrm{GaN} / \mathrm{A} 1_{x} \mathrm{Ga}_{1-x} \mathrm{~N}$ heterostructures grown by low pressure metalorganic chemical vapor deposition," Appl. Phys. Lett., to be published.

[67] S. Hiyamizu, T. Mimura, T. Fuji, and K. Nanbu, "High mobility of two-dimensional electrons at the GaAs/n-A1GaAs heterojunction interface," Appl. Phys. Lett., vol. 37, pp. 805-807, Nov. 1980.

[68] Z. Sitar, M. J. Paisley, B. Yan, J. Ruan, and J. W. Choyke, and R. F. Davis, "Growth of AIN/GaN layered structures by gassource molecular beam epitaxy,"J. Vac. Sci. Technol. B, vol. 8, pp. 316-322, Mar./Apr. 1989.

[69] J. B. MacChesney, P. M. Bridenbaugh, and P. B. O'Connor, "Thermal stability of indium nitride at elevated temperatures and nitrogen pressures," Mater. Res. Bull., vol. 5, pp. 783-792, June 1970.

[70] H. J. Hovel, and J. J. Cuomo, "Electrical and optical properties of RF-sputtered GaN and InN," Appl. Phys. Lett., vol. 20, pp. 71-73, Jan. 1972

[71] B. R. Natarajan, A. H. Eltoukhy, J. E. Green, and T. L. Barr, "Mechanisms of reactive sputtering of indium I: growth of InN in mixed $\mathrm{Ar}-\mathrm{N}_{2}$ discharges; II: Growth of indium oxynitride in mixed $\mathrm{N}_{2}-\mathrm{O} 2$ discharges," Thin Solid Films, vol. 68, pp. 201-235, 1979.

[72] T. L. Tansley and C. P. Foley, "Optical bandgap of indium nitride,” J. Appl. Phys., vol. 59, pp. 3241-3244, May 1986.

[73] B. T. Sullivan, R. R. Parsons, K. L. Westra, and M. J. Brett, "Optical properties and microstructure of reactively sputtered indium nitride thin films," J. Appl. Phys., vol. 64, pp. 4144-4149, Oct. 1988.

[74] J. W. Trainor and K. Rose, "Some properties of InN films prepared by reactive evaporation," J. Electronic Mater., vol. 3, pp. 821-828, Apr. 1974

[75] L. A. Marasina, I. G. Pichugin, and M. Tlaczala, "Preparation of InN epitaxial layers in $\mathrm{InCl}_{3}-\mathrm{NH}_{3}$ System," Krist Technol., vol. 12, pp. 541-545, June 1977.

[76] S. Masaki, K. Sudou, H. Kobayashi, and H. Morisaki, in Proc Twelfth Symp. Ion Sources and ion-Assisted Technol., T. Takagi Ed., published as a collection of papers by the Research group on Ion Engineering, Kyoto University, Kyoto, Japan, 1989, pp. 391-394.

Robert F. Davis, for a photograph and biography please see page 598 of this issue. 